\title{
Poverty, Gender and Education in Lesotho
}

\author{
Tiisetso Makatjane \\ Department of Demography \\ National University of Lesotho \\ P. O. Roma 180 \\ Lesotho
}

\begin{abstract}
The present study used the 2001 Lesotho Demographic Survey to investigate differences in poverty between male and female headed households in Lesotho. Constructed quality of housing and amenities, economic characteristics of household members aged 10 years and above as well as children's participation in education were used as proxies for household well-being. The data consist of more than sixteen thousand households with more than 28 thousand children aged 5-18 years. Both descriptive and multivariate regression analysis were used in the study. Generally males head the majority of households in Lesotho and are concentrated in male headed households. Male heads were currently married while female heads were previously married. Male headed households were economically better off than female headed households. Similar variables were found to be influencing constructed household wealth in both male and female headed households. Orphaned children's participation in education was at par with the other children if they resided in female headed households while child birth experience disadvantages female children. Introduction of free primary education has not eliminated differences in participation rates between male and female children while female children's participation in education is enhanced if they reside in male headed households.
\end{abstract}




\section{Introduction}

Since the beginning of the 1990s a number of studies have documented the level of poverty in Lesotho (Sechaba Consultants, 1990, 1994, 2000; UNDP, 1994). Unfortunately, these studies do not make a distinction between male and female headed households. However, as early as the 1980s studies on poverty and gender had already established beyond reasonable doubt that female headed households are poorer than male headed households (Peters, 1983; Kossoudji and Mueller, 1983). Furthermore, recent studies have also established that in Lesotho female headed households are at an economic disadvantage relative to their male headed counterparts (Makatjane, 1990; Mturi et al. 1999; Tuoane et al. 2001). These recent studies have also established the impact of this relative disadvantage of female headed households on the well being of members of these households. According to Mturi et al. (1999), female headed households are a disadvantaged group in terms of owning standard household possessions while Tuoane and others (2001) conclude that children in female headed households have less chances of secondary education that children in male headed households due to poverty of their households. What is missing in Tuoane's study is the role of children's relationship to the household head in influencing children's participation in education.

Studies elsewhere have also shown that it is not only the sex of the household head which is correlated with poverty and children's participation in schooling but household structure and composition also play a part (Townsend et al., 2002). According to Townsend and others (2002), the proportion of children aged less than 15 years in the household impacts on the children's participation in education. The apparent difference in the demographic household compositions of male and female headed households (Tuoane et al. 2001) might have a bearing on the relative low participation of children in female headed households' participation in education.

It is common knowledge that HIV/AIDS is a problem in the whole of Africa and in Lesotho in particular. The obvious implications of this problem is an increasing number of orphans. For instance, according to the 1986 and 1996 Lesotho Population Census figures the proportion of population aged less than 25 years 
with both parents dead was constant at 0.006 and increased three fold to 0.019 between 1996 and 2001 (Bureau of Statistics, 1991, 1998 and 2002). The role of orphanhood on the children's participation in education has not been empirically established in Lesotho. The Lesotho 2001 Demographic Survey provides an opportunity to investigate the plight of orphans with regard to participation in education.

While poverty is multi-dimensional and monetary value is often used as its indicator such as use of one American dollar as the bare minimum as a means of survival, there are other indicators such as access to decent housing, education and amenities which are equally important. Household characteristics such as the type of housing materials do provide information which can be used as indicators of poverty as well as children's participation in education. The 2001 Lesotho Demographic Survey provides an opportunity to use housing characteristics and children's participation in education to compare poverty between male and female headed households in Lesotho as well as investigating the differences of the impact of poverty on the children's participation in education. Last, the survey data provides an opportunity to investigate whether participation in primary education disparities between male and female children have disappeared as a result of the introduction of free primary education in Lesotho.

The present study uses the 2001 Lesotho Demographic Survey to include household structure and orphanhood into the equation in trying to understand the relationship between poverty, gender and children's participation in education. Separate analysis is done for information from male and female headed households. Comparisons of indicators of poverty or development are made using the sex of the household head as the unit of analysis. This is an aspect which is missing in the analysis of the 2001 Lesotho Demographic Survey.

This paper has a double objective. It is first aimed at investigating the differences in poverty between male and female headed households using economic characteristics, children's participation in education and quality of housing and amenities as proxies for poverty. Secondly the paper seeks to establish if poverty and differences in socio demographic characteristics of both the household head and those of children impact on the children's participation in education. 


\section{Source of Data}

The source of data for the present study is the 2001 Lesotho Demographic Survey. Lesotho Demographic Survey was a nationally representative sample that was conducted in May 2001 and it covered over sixteen thousand households. More than twenty eight thousand children aged between 5 and 18 were selected for analysis of children " participation in education. Officially, six is the recommended age of entry into primary education but five year olds have been selected for analysis. This was because a third of these children were reported as attending school. For purposes of sub-dividing the population into primary and secondary attendance, population aged 5-14 is assumed to be attending primary while those aged 15-18 are to be attending secondary education. The study relies mainly on the household information of the survey. Details of the survey design and other important aspects of the survey are given in the 2001 Lesotho demographic Survey Analytical Report Volume I (Bureau of Statistics, 2002).

The following information was extracted for use in the analysis: orphanhood status of the children, children's relationship to the household head, education, occupation and migrant worker status of the head. Household information such as the proportion of population aged less than 15 years in the household, proportion of wage/salary earners to population aged 12 years and above, number of migrant workers and population aged less than 15 years as well as household size were also attached to the child's data file. Current school attendance is used to measure children's participation in education. The use of information on current school attendance is a better indicator of the present financial position of the household as opposed to using completed education as that refers to the past when the economic position of the household would have been different particularly for female headed households whose heads are generally widowed.

\section{Methodology}

Both descriptive and multivariate methods of analysis are used in the study. The descriptive analysis is used to describe the observed children's participation rates in education, household characteristics of both members and those of the household head and household wellbeing using constructed household wealth as a 
proxy for household wealth. Logistic regression analysis is used to establish the importance of the selected variables in influencing chances of participation in education for children while multivariate linear regression is used to investigate some determinants of household poverty.

Tuoane et al. (2001) constructed household wealth indicator using household possessions and characteristics as a summary measure that enabled comparison of wealth difference between male and female headed households. The 2001 Demographic Survey does not have some of the information contained in the 1994/95 Household Budget Survey to enable one to construct a similar wealth index. Possession of livestock, poultry and material things like vehicle are missing from the present data. However, an index based on the rest of the other household possessions and characteristics is still constructed in order to have a summary measure of wealth in the households and investigate some determinants of this index as well as investigating how this index influences children's participation in education. Two indices are constructed for the quality of housing and amenities while the third index is the sum of the two. For the quality housing index, material for the construction of walls, floor and roofing are used while for the quality of amenities fuel for cooking, heating and lighting, sources of drinking water, possession of a working radio and quality of toilet facilities are used. The weighted sum of the housing materials and type of fuel used in the household as well as the type of toilet facility and source of water constitute the two indices. The weights used for each of the materials are as shown in Table 1. The present approach is similar to the one used by Mturi et al. (1999) and Tuoane et al. (2001) for the 1994/95 Lesotho Household Budget Survey except for the missing information as already indicated. 
Table 1: Weights Used for the Construction of Quality Variables

\begin{tabular}{|c|c|c|c|c|}
\hline \multicolumn{4}{|c|}{ Weights } & \multirow[b]{3}{*}{ cement brick } \\
\hline Material & $\mathbf{0}$ & $1 \quad 2$ & & \\
\hline Wall Material: & $\begin{array}{l}\text { Stick and mud } \\
\text { Mud bricks, other }\end{array}$ & stones & burned bricks & \\
\hline $\begin{array}{l}\text { Floor material: } \\
\text { Roofing material }\end{array}$ & $\begin{array}{l}\text { wood, other } \\
\text { thatch, other }\end{array}$ & $\begin{array}{l}\text { mud \& dung } \\
\text { corrugated iron }\end{array}$ & $\begin{array}{l}\text { cement } \\
\text { tiles }\end{array}$ & tiles \\
\hline Fuel for cooking & $\begin{array}{l}\text { wood, other } \\
\text { Cow dung } \\
\text { Crop waste }\end{array}$ & coal, paraffin & gas & eléctricity \\
\hline Fuel for heating & $\begin{array}{l}\text { wood, other } \\
\text { Cow dung }\end{array}$ & coal, paraffin & gas & electricity \\
\hline Fuel for lighting & $\begin{array}{l}\text { paraffin, candles } \\
\text { Other }\end{array}$ & gas & electricity & \\
\hline $\begin{array}{l}\text { Toilet facility } \\
\text { Source of water } \\
\text { Working radio }\end{array}$ & $\begin{array}{l}\text { no toilet, bucket } \\
\text { river, other } \\
\text { none }\end{array}$ & $\begin{array}{l}\text { pit latrine } \\
\text { spring }\end{array}$ & $\begin{array}{l}\text { VIP } \\
\text { well borehole } \\
\text { Catchment tank } \\
\text { available }\end{array}$ & $\begin{array}{l}\text { water system } \\
\text { piped }\end{array}$ \\
\hline
\end{tabular}




\section{Findings}

\section{Social and Demographic Characteristics}

Table 2 presents the characteristics of the household head and household composition. The figures are typical of the household structure of Lesotho as well as the characteristics that have been established in the past (Makatjane, 1990; Mturi et al. 1999; Tuoane et al. 2000). In summary, the age structure of Lesotho's population is a youthful one and this is the case irrespective of the sex of the household head. The majority of male heads are presently married while female heads are previously married. The majority of households are found in the rural areas and most heads were present in the household during the survey. The relatively high proportion of male heads with no education is typical of Lesotho where females' participation in education in higher than that of males. Residential status information indicates that the majority of heads were present during the survey. However, male heads are more prone to international migration as evidenced by the high proportion of heads who were outside the country during the survey. 


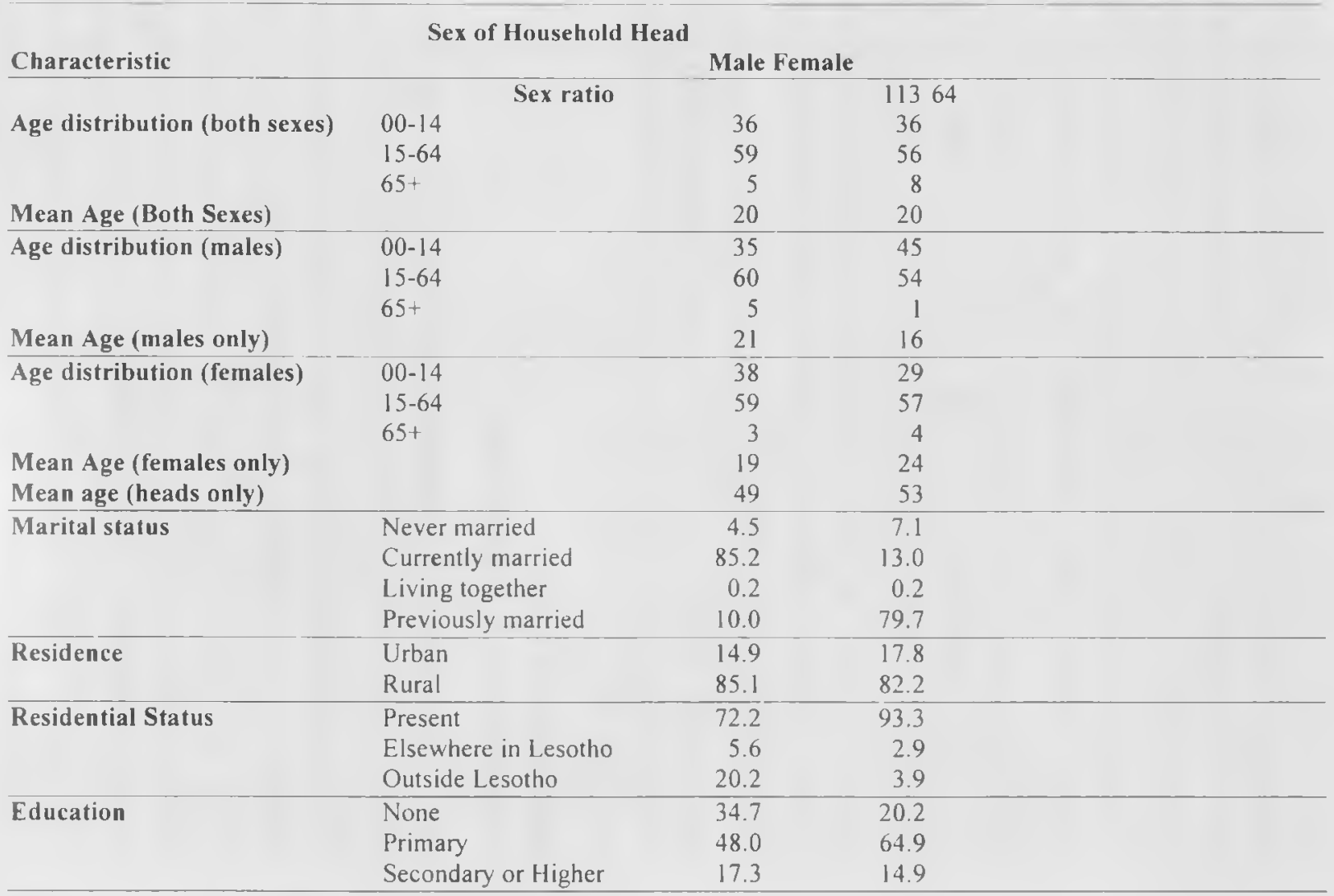


There is an apparent shortage of males in female headed households. This is evidenced by the low sex ratio of 64 males per hundred females while a sex ratio of 113 males per hundred females in male headed households in indicative of the high concentration of males in male headed households. The mean age of 16 for males in female headed households is also indicative of absence of adult males in female headed households. The age distribution of the population for both sexes is similar between male and female headed households. Comparing males and females separately, there is a high concentration of male children in female headed households (45 percent as opposed to 35 percent in male headed households) and a higher concentration of female children (38 percent as against 29 percent in female headed households). There is also a 4 percent difference in favour of male headed households for population of males aged 15-64.

It is also observed in Table 2 that male heads are younger than female heads. With a mean age of 56 years, females heads are 8 years older than their male counterparts. This is in order given that more than a third of female heads are widowed.

\section{Household well being}

\section{Socio-Economic Characteristics}

Table 3 presents socio economic characteristics of the population and constructed quality of housing and amenities. According to the figures in Table 3, working in South Africa is pronounced in male headed households and among males in particular. Except where females only are compared, the proportion of individuals in male headed households who were presently working in South Africa during the survey is about twice that of individuals residing in female headed households. It is also noteworthy that the proportion presently working in South Africa is highest among household heads. It is apparent from the figures that wage or salary earners are concentrated in male headed households. Wage or salary earners as a percentage of population aged 10 years and above is higher in male headed households except when comparing females only. Male heads are more prone to migration to South A frica as reflected in the high proportion of male heads reported as residing outside Lesotho during the survey. 


\section{Characteristic}

\section{Sex of Household Head}

Presently working in South Africa (both sexes aged 10+)

Male

Female

Presently working in South Africa (males 10+)

Presently working in South Africa (females 10+)

$13-7$

Presently working in South Africa (heads only)

Wage/salary earners as a $\%$ of population aged $10+$ (both sexes)

34

Wage/salary earners as a $\%$ of population aged $10+$ (males)

37

Wage/salary earners as a $\%$ of population aged $10+$ (females)

Quality of Housing

$0-1$

2

3

37

16

Quatity of Housing

Quality of Amenities

Mean

19

26

11

\begin{tabular}{ll}
\hline Quality of Amenities & $0-2$ \\
& $3-5$ \\
& $6-8$ \\
& $9+$ \\
\hline Note & Mean \\
Source: & Mean differences are statistically significant at 1\% level
\end{tabular}

\begin{tabular}{rr}
28.8 & 34.8 \\
26.9 & 31.2 \\
38.5 & 30.5 \\
5.8 & 3.5 \\
\hline 1.4 & 1.3 \\
\hline 17.3 & 17.9 \\
46.3 & 47.9 \\
25.0 & 24.0 \\
11.3 & 10.2 \\
\hline 2.3 & 2.2 \\
\hline
\end{tabular}

Source:

Mean differences are statistically signif
2001 Lesotho Demographic Survey 


\section{Quality of Housing and Amenities}

As was the case in studies of Mturi et al (1999) and Tuoane et al. (2001) the quality of housing and amenities in male headed households is better than what is prevailing in female headed households according to the means of these quantities. Constructed quality of housing and amenities coupled with economic characteristics suggest that female headed households are poorer than male headed households. Moreover, the proportion of female headed households with a quality of housing score less than the average for all households irrespective of the sex of the household head is 67 percent as opposed to 57 percent in male headed households. Comparative figures for the constructed quality of amenities are 63 percent and 70 percent respectively for male and female headed households (Table 3).

Multiple linear regression was carried out to investigate some determinants of constructed household wealth. Since the assumption of normality is crucial in order to have faith in the conclusions of the multiple linear regression, the histogram and the normal probability plot is used to test the assumption of normality. Figure 1 presents the histograms and the normal probability plots for the entire sample and separately for male and female headed households. The visual inspection indicates that linear regression analysis is appropriate for the data.

Regarding determinants of household wealth, similar variables are influencing constructed household wealth among male and female headed households (Table 4). The majority of variables have the expected sign of the coefficients except for a few. This is the case with the age of head and number of miners. Since wealth is accumulated over time older heads should be wealthier than their younger counterparts but this is not what is suggested by the coefficient associated with age in Table 4 . The same goes for the number of miners where one expected that a higher number of household members presently working in South Africa should be positively associated with constructed household wealth. The figures in Table 4 further demonstrate that urban and male headed households are wealthier than their rural and female headed counterparts. 
Table 4: Coefficients and standard errors in brackets of the relationship between constructed household wealth and selected variables, Lesotho 2001

\begin{tabular}{lccc}
\hline Variable & Both sexes & Male Head & Female Head \\
\hline Constant & $6.236^{* *}(0.083)$ & $6.944^{* *}(0.093)$ & $6.287^{* *}(0.131)$ \\
Age of head & $-0.017^{* *}(0.001)$ & $-0.018^{* *}(0.002)$ & $-0.017^{* *}(0.002)$ \\
Education of head & $0.268^{* *}(0.004)$ & $0.274^{* *}(0.005)$ & $0.244^{* *}(0.008)$ \\
Salaried workers & $0.378^{* *}(0.023)$ & $0.442^{* *}(0.027)$ & $0.131^{* *}(0.043)$ \\
Household size & $0.131^{* *}(0.010)$ & $0.123^{* *}(0.013)$ & $0.158^{* *}(0.018)$ \\
Number of children & $-0.261^{* *}(0.015)$ & $-0.258^{* *}(0.018)$ & $-0.283^{* *}(0.026)$ \\
Rural urban residence (1 urban; 0 rural) & $3.588^{* *}(0.057)$ & $3.625^{* *}(0.072)$ & $3.516^{* *}(0.090)$ \\
Number of miners & $-0.499^{* *}(0.039)$ & $-0.591^{* *}(0.051)$ & $-0.252^{* *}(0.061)$ \\
Sex of household head (I male, 0 female) & $0.665^{* *}(0.037)$ & na & na \\
\hline R square & 0.35 & 0.34 & 0.36 \\
Adjusted R square & 0.35 & 0.34 & 0.36 \\
\hline
\end{tabular}

Note $\quad * * 0.001 \%$

Source: $\quad 2001$ Lesotho Demographic Survey 


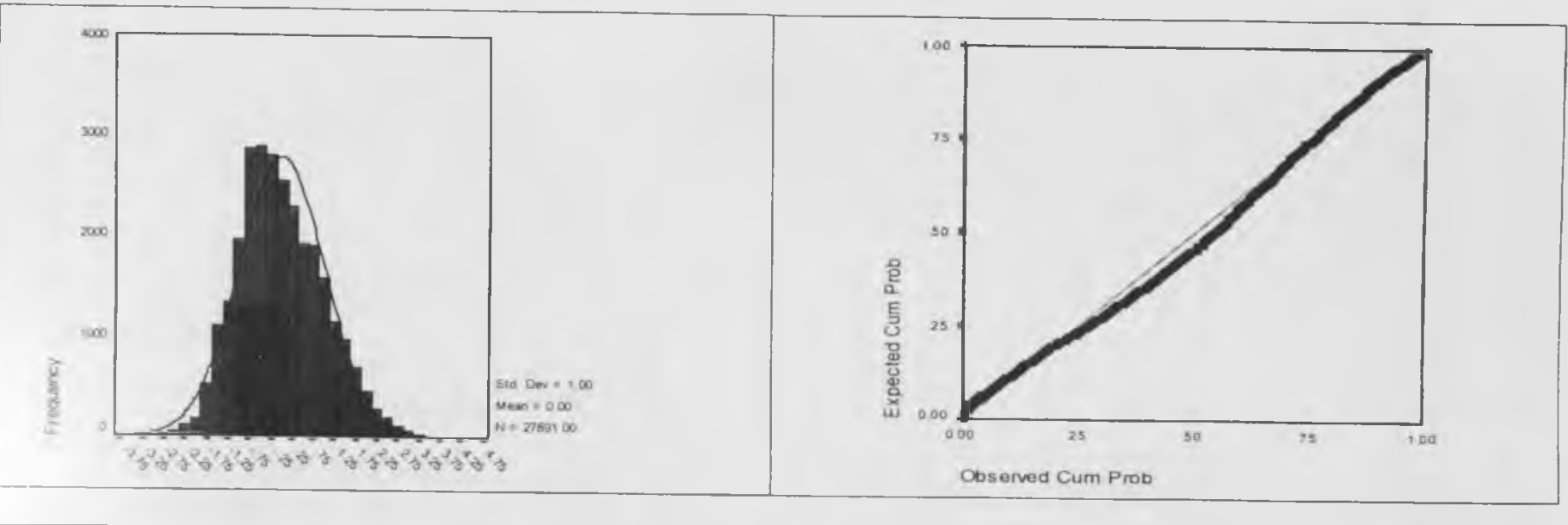

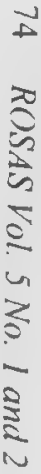

Histogram: Male Headed Households
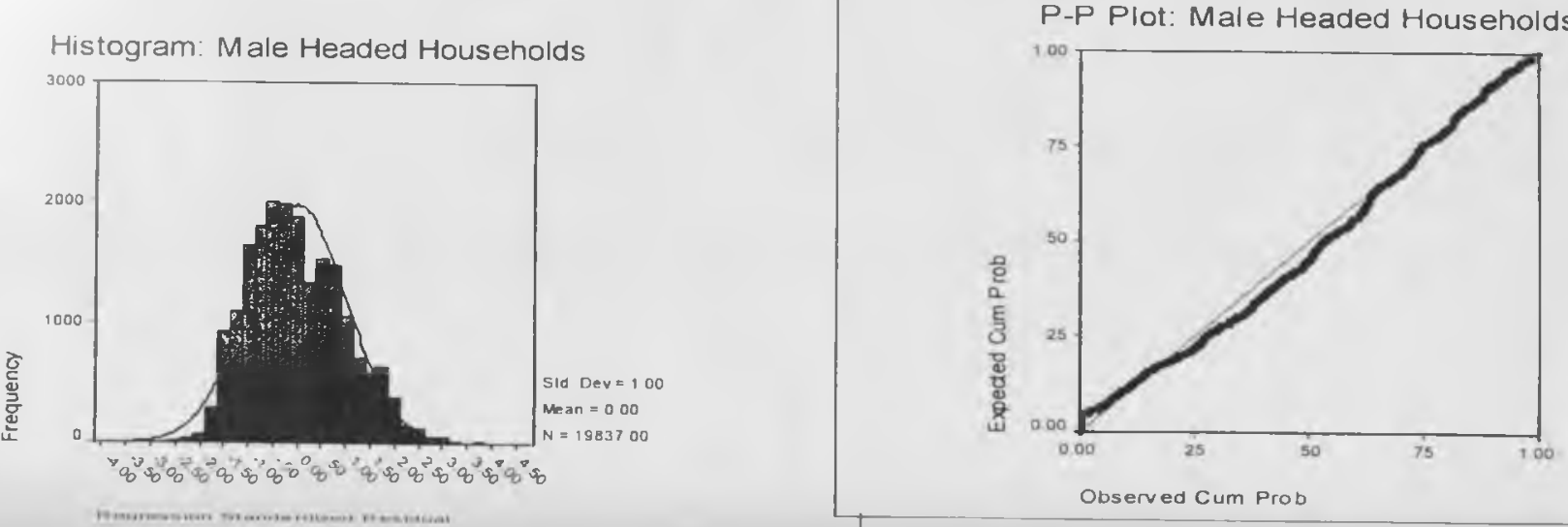


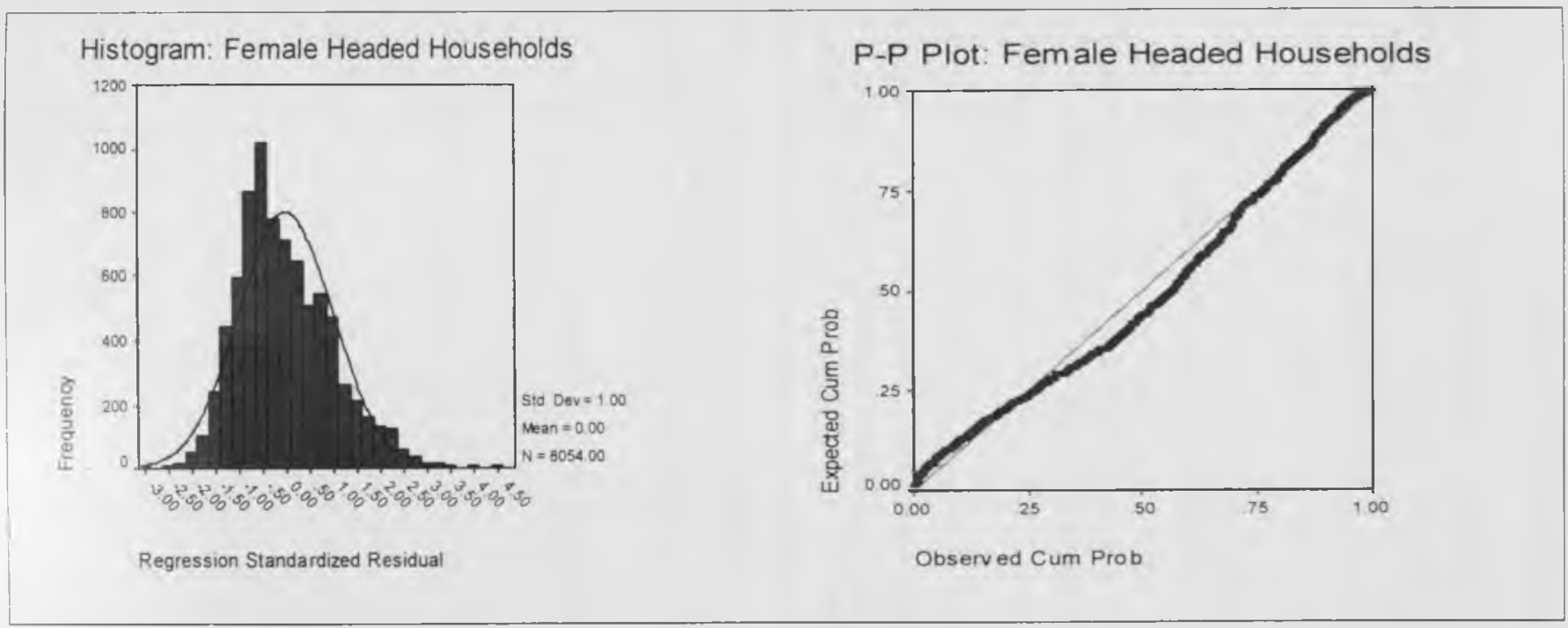

Figure 1: Histograms and Probability Plots of Standardised Residuals versus Normal Quintiles for both Sexes and male and female headed households separately. 


\section{Children's Participation in Education}

Table 5 presents children's participation rates in education by selected socio-demographic variables. At primary level, children's participation in education is similar between male and female headed households. However, participation rates of female children are higher than those of male children and this is true for all the variables irrespective of the sex of household head. At secondary level, children in male headed households have higher participation rates than children in female headed households. Female children continue to have higher participation rates as was the case in primary education. It is also noteworthy that participation of male children is not influenced by the sex of the household head while female children are better off if they reside in male headed households.

For both primary and secondary the figures in Table 5 suggest a positive relationship between constructed wealth and children's participation in education. For the other variables there is no clear cut relationship. The figures generally suggest no relationship or a negative one. For instance, the participation of children residing in households with no migrants or workers participate in education more than children residing in households with two or more migrants or workers and this is true for both primary and secondary. 
Table 5: School Participation of Population Aged 5-18 by Sex of Household Head, Sex of the Child and Selected Variables: Lesotho 2001 Demographic Survey

\begin{tabular}{|c|c|c|c|c|c|c|c|c|c|}
\hline \multirow[b]{3}{*}{ Variable } & & \multicolumn{3}{|c|}{ Primary Education } & & \multicolumn{4}{|c|}{ Secondary Education } \\
\hline & & \multicolumn{2}{|c|}{ Male Head } & \multicolumn{2}{|c|}{ Female Head } & \multicolumn{2}{|c|}{ Male head } & \multicolumn{2}{|c|}{ Female Head } \\
\hline & & Male & Female & Male & Female & Male & Female & & Male Female \\
\hline Constructed & $0-4$ & 63 & 78 & 70 & 78 & 41 & 58 & 44 & 54 \\
\hline \multirow[t]{3}{*}{ Wealth } & $5-9$ & 81 & 86 & 81 & 85 & 57 & 66 & 59 & 62 \\
\hline & $10-14$ & 88 & 90 & 87 & 93 & 75 & 75 & 79 & 68 \\
\hline & $15+$ & 92 & 94 & 97 & 98 & 88 & 71 & 91 & 61 \\
\hline Number of & 0 & 78 & 85 & 79 & 84 & 58 & 67 & 58 & 61 \\
\hline Male & 1 & 74 & 83 & 79 & 83 & 52 & 64 & 56 & 54 \\
\hline Migrants & $2+$ & 67 & 62 & 70 & 85 & 44 & 70 & 50 & 66 \\
\hline Number of & 0 & 77 & 85 & 79 & 84 & 58 & 67 & 58 & 60 \\
\hline Female & 1 & 82 & 81 & 75 & 75 & 60 & 66 & 57 & 59 \\
\hline Migrants & $2+$ & 65 & 77 & 66 & 83 & 50 & 43 & 58 & 81 \\
\hline Number of & 0 & 79 & 85 & 80 & 83 & 64 & 67 & 62 & 61 \\
\hline Male & 1 & 75 & 87 & 76 & 86 & 45 & 66 & 54 & 60 \\
\hline \multirow[t]{2}{*}{ Workers } & 2 & 58 & 80 & 66 & 86 & 37 & 70 & 33 & 64 \\
\hline & $3+$ & 59 & 89 & 54 & 86 & 34 & 54 & 36 & 40 \\
\hline Number of & 0 & 76 & 85 & 79 & 84 & 56 & 69 & 57 & 65 \\
\hline Female & 1 & 83 & 86 & 79 & 85 & 65 & 66 & 63 & 45 \\
\hline \multirow[t]{3}{*}{ Workers } & 2 & 83 & 84 & 79 & 79 & 77 & 50 & 59 & 48 \\
\hline & $3+$ & 85 & 80 & 42 & 73 & 72 & 41 & 83 & 67 \\
\hline & Total & 78 & 85 & 79 & 84 & 58 & 67 & 58 & 61 \\
\hline
\end{tabular}

Source: $\quad 2001$ Lesotho Demographic Survey 
Table 6a:

Coefficients and odds ratios for the relationship between children's participation in primary education and selected variables, Lesotho 2001

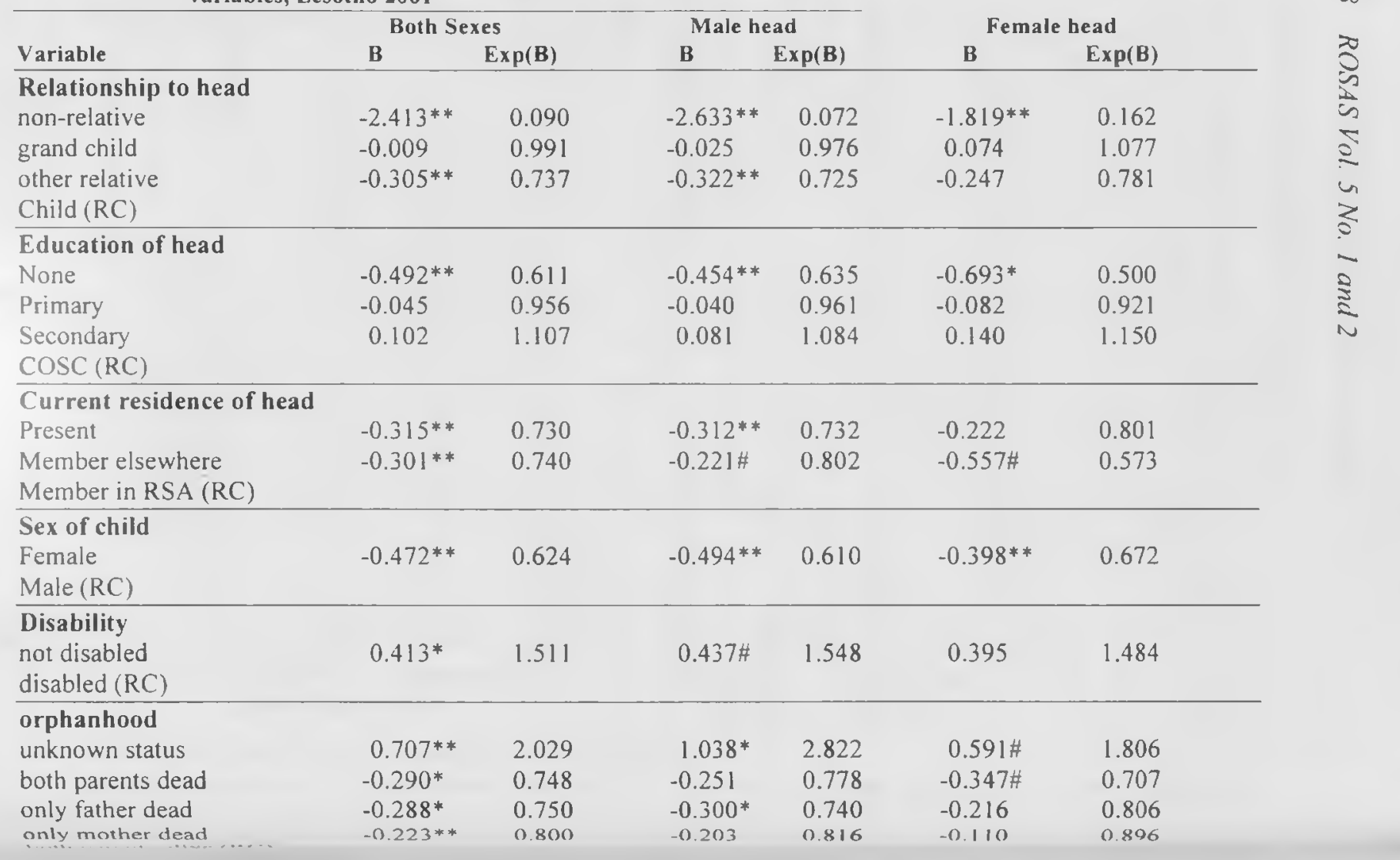




\section{Sex of head}

\begin{tabular}{|c|c|c|c|c|c|c|}
\hline $\begin{array}{l}\text { Female } \\
\text { Male (RC) }\end{array}$ & -0.063 & 0.939 & na & na & nа & na \\
\hline age of child & $0.338 * *$ & 1.402 & $0.335^{* *}$ & 1.398 & $0.351 * *$ & 1.421 \\
\hline age of head & 0.001 & 1.001 & -0.003 & 0.997 & $0.010^{*}$ & 1.010 \\
\hline Wealth & $0.128 * *$ & 1.137 & $0.125^{* *}$ & 1.133 & $0.144 * *$ & 1.155 \\
\hline Male migrants & 0.089 & 1.094 & -0.051 & 0.950 & $0.295^{*}$ & 1.343 \\
\hline Female migrants & -0.067 & 0.935 & 0.011 & 1.011 & -0.170 & 0.843 \\
\hline Male workers & $-0.178 * *$ & 0.837 & $-0.167 * *$ & 0.846 & $-0.184^{*}$ & 0.832 \\
\hline Female workers & -0.004 & 0.996 & 0.015 & 1.015 & -0.056 & 0.946 \\
\hline Children & -0.029 & 0.971 & $-0.044 \#$ & 0.957 & 0.005 & 1.005 \\
\hline Household size & -0.004 & 0.996 & 0.014 & 1.014 & -0.029 & 0.971 \\
\hline Constant & $-1.649 * *$ & & $-1.548 * *$ & & $-2.419 * *$ & \\
\hline Cox \& Snell R Square & \multirow{2}{*}{\multicolumn{2}{|c|}{$\begin{array}{l}14 \\
22\end{array}$}} & \multicolumn{2}{|l|}{14} & \multicolumn{2}{|c|}{14} \\
\hline Nagelkerke R Square & & & \multicolumn{2}{|l|}{21} & \multicolumn{2}{|c|}{24} \\
\hline
\end{tabular}

Notes \#p<0.10,* $p<0.05 ;{ }^{* *} p<0.01$

Source: $\quad 2001$ Lesotho Demographic Survey 
Table 6b: Coefficients and odds ratios for the relationship between children's participation in secondary education and selected variables, Lesotho 2001

\begin{tabular}{|c|c|c|c|c|c|c|c|c|}
\hline \multirow[b]{2}{*}{ Variable } & \multicolumn{2}{|c|}{ Both Sexes } & \multicolumn{2}{|c|}{ Male head } & \multirow{2}{*}{\multicolumn{2}{|c|}{$\begin{array}{c}\text { Female head } \\
\text { B } \operatorname{Exp}(B)\end{array}$}} & \multirow{2}{*}{\multicolumn{2}{|c|}{ Girls onl }} \\
\hline & & $\operatorname{Exp}(B)$ & B E & $\operatorname{xp}(B)$ & & & & \\
\hline \multicolumn{9}{|c|}{ Relationship to head } \\
\hline Non-relative & $\begin{array}{l}-2.165^{* *} \\
0.178\end{array}$ & 0.115 & $-2.581^{* *}$ & 0.076 & $-1.073^{* *}$ & 0.342 & $-1.724 * *$ & \\
\hline Grand child & $0.310^{* *}$ & 1.364 & $0.280^{*}$ & 1.323 & $0.453^{* *}$ & 1.572 & 0.034 & 1.035 \\
\hline Other relative & $\begin{array}{c}-0.620^{* *} \\
0.559\end{array}$ & 0.534 & $-0.792 * *$ & 0.453 & -0.141 & 0.869 & $-0.581 * *$ & \\
\hline \multicolumn{9}{|c|}{ Child (RC) } \\
\hline \multicolumn{9}{|c|}{ Education of head } \\
\hline None & $\begin{array}{l}-0.917^{* *} \\
0.560\end{array}$ & 0.400 & $-0.861 * *$ & 0.423 & $-1.130 * *$ & 0.323 & $-0,580^{* *}$ & \\
\hline Primary & $-0.613 * *$ & 0.452 & $-0.553 * *$ & 0.575 & $-0.717 * *$ & 0.488 & $-0.392 *($ & 0.676 \\
\hline $\begin{array}{l}\text { Secondary } \\
\text { COSC (RC) }\end{array}$ & 0.162 & 1.172 & 0.263 & 1.301 & -0.036 & 0.965 & 0.133 & 1.142 \\
\hline \multicolumn{9}{|c|}{ Current residence of head } \\
\hline Present & $\begin{array}{l}-0.450^{* *} \\
0.578\end{array}$ & 0.638 & $-0.463 * *$ & 0.630 & $-0.364 \#$ & 0.695 & $-0.547^{* *}$ & \\
\hline $\begin{array}{l}\text { Member elsew } \\
\text { Member in RS }\end{array}$ & $\begin{array}{l}\text { re- } 0.244^{*} \\
(\mathrm{RC})\end{array}$ & 0.783 & $-0.254 \#$ & 0.776 & -0.118 & 0.888 & $-0.457^{*}$ & 0.633 \\
\hline $\begin{array}{l}\text { Sex of child } \\
\text { Male } \\
\text { Female (RC) }\end{array}$ & $-0.244^{* *}$ & 0.783 & $-0.306^{* *}$ & 0.736 & -0.059 & 0.943 & na & na \\
\hline Disability? & & & & & & & & \\
\hline
\end{tabular}




\begin{tabular}{|c|c|c|c|c|c|c|c|c|}
\hline $\begin{array}{l}\text { Sex of head } \\
\text { Male } \\
\text { Female (RC) }\end{array}$ & -0.42 & 0.959 & па & na & na & na & -0.026 & 0.975 \\
\hline \multicolumn{9}{|l|}{ Orphanhood } \\
\hline Unknown status & 0.324 & 1.412 & 0.582 & 1.789 & 0.387 & 1.472 & 0.348 & 1.416 \\
\hline Both parents dead & $-0.428 * *$ & 0.652 & $-0.389 *$ & 0.678 & -0.327 & 0.721 & $-0.398^{*}$ & 0.672 \\
\hline Only father dead & $-0.293^{*}$ & 0.008 & $-0.324^{*}$ & 0.723 & -0.113 & 0.893 & $-0.486^{* *} \mathrm{C}$ & 0.615 \\
\hline Only mother dead & $-0.270^{* *}$ & 0.763 & $-0.239 \#$ & 0.787 & -0.001 & 0.999 & $-0.397 * * C$ & 0.672 \\
\hline \multicolumn{9}{|c|}{ Both parent alive (RC) } \\
\hline \multicolumn{9}{|c|}{ Ever given birth? } \\
\hline \multicolumn{9}{|l|}{ Yes (RC) } \\
\hline Age of child & $\begin{array}{l}-0.488^{* *} \\
0.637\end{array}$ & 0.614 & $-0.501^{* *}$ & 0.606 & $0.462^{* *}$ & 0.630 & $-0.4451^{* *}$ & \\
\hline Age of head & $-0.010^{* *}$ & 0.990 & $-0.014^{* *}$ & 0.986 & -0.005 & 0.995 & -0.005 & 0.995 \\
\hline Wealth & $0.126^{*}$ & 1.134 & $0.122 * *$ & 1.130 & $0.133^{* *}$ & 1.143 & $0.096 * *$ & 1.101 \\
\hline Male migrants & 0.016 & 1.016 & -0.006 & 0.994 & 0.122 & 1.129 & -0.172 & 0.842 \\
\hline Female migrants & $0.196^{*}$ & 1.217 & 0.045 & 1.046 & $0.516^{* *}$ & 1.675 & $0.402 * *$ & 1.495 \\
\hline Male workers & $-0.256^{* *}$ & 0.774 & $-0.209 * *$ & 0.811 & $-0.362^{* *}$ & 0.697 & 0.077 & 1.080 \\
\hline Female workers & $-0.196^{* *}$ & 0.822 & $-0.124^{*}$ & 0.883 & $-0.416^{* *}$ & 0.660 & $-0.462 * *$ & 0.630 \\
\hline Children & $-0.173^{* *}$ & 0.841 & $-0.179^{* *}$ & 0.836 & $-0.169^{* *}$ & 0.845 & $-0.134^{* *}$ & 0.874 \\
\hline Household size & $0.113^{* *}$ & 1.120 & $0.116^{* *}$ & 1.123 & $0.109^{* *}$ & 1.115 & $0.080^{* *}$ & 1.084 \\
\hline Constant & $8.655^{* *}$ & & $9.131^{* *}$ & & $7.462^{* *}$ & & $6.094 * *$ & \\
\hline \multicolumn{3}{|c|}{$\begin{array}{c}\text { Cox \& Snell R squared } \\
19\end{array}$} & 19 & & 21 & & 16 & \\
\hline \multicolumn{2}{|c|}{ Nagelkerke R Square } & 26 & & 29 & & 21 & & 26 \\
\hline $\begin{array}{ll}\text { Notes } & \# p \\
\text { Source: } & 20(\end{array}$ & $01 \mathrm{Les}$ & & $\begin{array}{l}0.01 \\
\text { Surve }\end{array}$ & & & & & \\
\hline
\end{tabular}




\section{Discussion}

Economic information, children's participation in secondary education and constructed household wealth do suggest that female headed households are poorer than male headed ones. The proportion of wage earners, population presently working in South Africa, constructed household wealth index and participation of children in secondary education are all significantly higher in male headed households than in female headed households. This is indicative of higher levels of poverty in female headed households. After controlling for the effects of other variables, multiple regression analysis results confirmed that male headed households are wealthier than their female headed counterparts.

Concerning determinants of constructed household wealth, age, education, number of migrants both female and male, number of salaried individuals in the household and sex of the household head are significantly related to constructed household wealth. These results are similar to what Mturi et al. (1990 and Tuoane et al. (2001) established using 1994/95 Lesotho Household Budget Survey.

The negative association between the age of the household head and the constructed household wealth is the opposite of what was found by Mturi et al. (1999) and Tuoane et al. (2001). Possible explanation could be the difference in the way the constructed household wealth is constructed. The household possessions such as livestock which are cumulated over time are not present for the 2001 data set but were used in the studies of Mturi et al. (1999) and Tuoane et al. (2001). As for the negative association between number of miners and constructed wealth, the findings on Mturi et al. (1999) which was restricted to urban areas did find a similar situation where the number of miners was negatively associated with constructed household wealth. Mturi and others argued that the relationship was indicative of the fact that migrant remittances were important in the rural areas (Mturi et al. 1999). In deed the findings of Tuoane et al. (2001), which used the same data but was for the whole country, migrant work was positively associated with constructed household wealth. The negative coefficient could still reflect the non-inclusion of possessions like livestock which is mainly a wealth status for rural men who are the majority of male migrants. It could also be an indication that migrant work is no 
longer the main source of livelihood in the rural areas as used to be the case in the past (Makatjane, 2000). Changes in the regulations governing the deferred payments of miners could not offer an explanation. In 1996 restrictions in the Deferred Pay (Amendment) Act, 1979 that migrant workers could not make more than 2 withdrawals and the amount of withdrawal should not exceed 50 percent of the deferred pay standing to an employee"s credit were repealed (Deferred Pay (Amendment) Act, 1995). If the money migrant workers were spending on their families was a result of the withdrawal restriction of their deferred pay, it is possible the negative coefficient between constructed household wealth and migrant worker status would suggest that migrants are not spending money on their families as was the case resulting from the change of the regulations. However, voluntary migrant remittances figures between 1993 and 2002 would not support such a claim. On average, the amount of remittances within this period has not changed (Central Bank of Lesotho, 1996; 1999; 2003) indicating that changes in the regulations governing deferred pay withdrawals could not be an explanation. The figures do not suggest any irresponsibility on the part of the migrants as the negative coefficient might suggest to some people. It would have been ideal to find out if changes in the regulations did bring a change in the regularity of withdrawals. Unfortunately, such information is not available due to its confidentiality.

The introduction of free primary education does not seem to have abolished education participation differences between male and female children in primary education. Female children continue to participate more than their male counterparts. It is, however, noted that participation in primary education is quite high, at around 80 percent, while participation in secondary education is less than 60 percent. Higher children's participation in primary education is in order given that primary education has always been cheaper than secondary education even before the introduction of Free Primary Education in 2000.

Participation in secondary education figures (bivariate and multivariate) do indicate that children from female headed households participate less in secondary education which is indicative of the economic position of these households. With 
analysis have identified the enabling environment (constructed household wealth) as important in influencing children's participation in education while variables such as education of head, number of children in the household, number of salaried workers, age of the child and household size are also important variables influencing children's participation in secondary education. It was also established that, in female headed households boys and girls have equal chances of participating in secondary education while in male headed households girls have a better chance. Orphanhood status of children is not associated with participating in education in female headed households as well as the age of the household head. Girls who have ever given birth to a child were also found to be less likely to participate in secondary education.

The findings of the study have policy implications for Lesotho. Free primary education is going to put a higher demand on the secondary schools which are already inadequate suggesting a need for a massive programme of building secondary schools to beef up the enrolment in secondary schools. Shortage of secondary schools have created a situation whereby placement of children in secondary education is increasingly in favour of those who pass their primary leaving examination with at least second class because of the high demand for secondary school places (Makatjane and Peko, 2002). The government policy that admission of pupils into secondary schools should give priority to catchment population of a particular school will work well if there is enough places for children in secondary schools hence the proposal of a massive programme for increasing places at secondary schools.

According to Peko (2000), unstandardised secondary education fees is another factor contributing to lower participation of children in secondary education as schools charge fees which might not be reflective of the needs of the school particularly when the government is paying all qualified teachers in the school. This argument is in line with the results of the multiple logistic regression analysis where an enabling environment as measured by the quality of both housing and amenities is an important influencing children's participation in secondary education. It is apparent that despite the fact that females have been seen elsewhere to be more supporting of education (Townsend et al. 2002), they are constrained by economic means hence the lower 
elsewhere to be more supporting of education (Townsend et al. 2002), they are constrained by economic means hence the lower participation rates in secondary education of children residing in female headed households compared to children residing in male headed households. Equal participation of children in primary education between male and female headed households when the financial burden of children's education is next to nothing, would support the argument that poverty in female headed households is a constraining factor for children's participation in secondary education for children in female headed households. The poverty of female headed holds is further supported by the higher participation of grand children compared to those of head as reflected in the logistic regression. It is a normal practice that young parents leave their children with their parents for one reason or another but still responsible for the well-being of the children. The results of the logistic regression are indicative of such a situation.

Understandably, HIV/AIDS is also having an impact on the participation of children in secondary education. The figures clearly show that the proportion of orphaned children has increased three fold between 1996 and 2001 and orphaned children have less chances of participating in education as evidenced by multiple logistic regression analysis except if they are staying in female headed households. One is aware that orphaned children are concentrated in female headed households which are mainly headed by widowed individuals with no access to financial resources. As evidenced by the results of Peko's study, the programme of helping orphaned children through social welfare is not working well, not to mention that it covers a small proportion of orphaned children. Obviously, the poverty of female headed households is not likely to improve under the circumstance. It is thus apparent that, once the child is orphaned, the chances of leading a better life in the future are doomed. It is, therefore, proposed that elimination of gender disparities along the lines suggested in the Gender and Development Policy is imperative as well as helping children in female headed households to participated more in secondary education in order to enhance their chances of leading a better future. 
such girls are discriminated against. This is more pathetic since in most cases the boy who impregnated the girl would still continue with education. One other form of discrimination has to do with disability of children. The findings do show that disabled children have less chances of participating in secondary education. One is aware though that the major constraining factor here is facilities for disabled children. There is need for decision makers to increase the facilities for disabled children in order for them to have equal chances of participating in secondary education like their counterparts who are not disabled. 


\section{References}

Bureau of Statistics (1991) Lesotho 1986 population Census

Tables vol. II, Bureau of Statistics Maseru Lesotho.

Bureau of Statistics (1999) Lesotho 1996 Population Census Tables vol. II, Bureau of Statistics Lesotho Maseru.

Bureau of Statistics (2002) 2001 Lesotho Demographic Survey Analytical Report, volume 1, Bureau of Statistics Maseru Lesotho.

Central Bank of Lesotho (1996) Quarterly Review Volume XV No 4, Maseru Lesotho.

Central Bank of Lesotho (1999) Quarterly Review Volume XVIII No 4, Maseru Lesotho.

Central Bank of Lesotho (2003) Quarterly Review Volume XXII No 2, Maseru Lesotho.

Deferred Pay (Amendment) Act, 1995

Kossoudji, S. and E. Mueller (1983) "The economic and demographic status of female-headed households in rural Botswana". Economic Development and Cultural Change 31 (4): 831-859.

Makatjane, Tiisetso (1990) Lesotho's Household Structure: Some Reflections from the Household Budget Survey. Working Paper No 18.

Makatjane, Tiisetso (2000) "Determinants of Family Planning Prevalence in Lesotho". Lesotho Social Sciences Review vol. 2(2): 146-161.

Makatjane, Tiisetso and Lebohang Peko (2002) "Determinants of Academic Performance of Secondary and High School Pupils in Lesotho" BOLESWA Educational Research Journal vol. 19:1-14

Mturi, A. J.; T. J. Makatjane and N. Molise (1999) "Gender differentials in housing characteristics and household possessions in Lesotho urban areas". GENUS - vol. LV-n 1-2 pages 121-133 
Peko, Palesa (2000) Rationalisation of Fees for Secondary and High Schools in Lesotho. Research Report Prepared for the Ministry of Education.

Peters, P. 1983 "Gender, Development Cycles and Historical Process: A Critique of Recent Research on Women in Botswana". Journal of Southern African Studies 10 (1): $100-122$

Sechaba Consultants (1990) Poverty in Lesotho: A Mapping Exercise. Maseru.

Sechaba Consultants (1994) Poverty in Lesotho. 1994: A Mapping Exercise. Maseru

Sechaba Consultants (2000) Poverty and Livelihoods in Lesotho, 2000: More Than a Mapping Exercise. Maseru.

Townsend, Nicholas, Sangeetha Madhavan, Stephen Tollman, Michel Garenne and Kathleen Kahn (2002) "Children's residence patterns and educational attainment in rural South Africa, 1997"

Tuoane, M; T. J. Makatjane; N. Mapetla (2001) "Gender Differentials and their Socio-Economic Implications on Household Headship in Lesotho". Paper presented at the International Conference on Gender, Population and Development in Africa, Abidjan, cote d'ivore, 16-21 July 2001.

United Nations Development Programme (1994) Human Development Report. New York: Oxford University Press. 


\section{(). (1) 99}

This work is licensed under a

Creative Commons

Attribution - NonCommercial - NoDerivs 3.0 License.

To view a copy of the license please see:

http://creativecommons.org/licenses/bv-nc-nd/3.0/ 